\title{
Exploring the Flexible Talent Introduction Mechanism for the Development of Airport industry in G City from the Perspective of Talent Governance
}

\author{
Liangmei Luo ${ }^{1, a}$, Xiaohui Wang ${ }^{2, *}$ \\ ${ }^{1}$ School of Public Administration, Xinhua college of sun yat-sen University, Tianhe, Guangzhou, China \\ ${ }^{2}$ Department of Business Management, Lingnan (University) College, Sun Yat-sen University, Guangzhou, China
}

\begin{abstract}
Promoting flexible talent introduction is an important part of innovative talent governance, and an effective mechanism to promote the flow of talents and release the vitality of talents. As an airport industry relying on resources such as convenient transportation, advanced logistics and strong radiation effects from large-scale hub airports, its core resources are still human resources. It is a strategic choice for the rapid development of the airport industry to quickly tap and introduce talents and give full play to the advantages of talents. At present, the theoretical and practical circles still lack in-depth discussions on the flexible talent introduction mechanism of the airport industry. This research focuses on the problems and causes analysis of the flexible introduction of talents in the airport industry in G City, and tries to start from the three governance concepts of collaborative governance, dynamic governance and risk governance, and proposes innovations in the talent policy system that promotes flexible introduction of talents, and innovations in talent introduction methods. Flexible introduction of countermeasures and suggestions for risk aversion. Hope to promote the in-depth study of the flexible talent introduction model.
\end{abstract}

\section{Issues and research ideas}

As With multiple advantages such as national strategic positioning, multiple transportation hubs, and multiple preferential policies, the Airport Economic Zone of City $\mathrm{G}$ is accelerating the accumulation of high-end industries in the region in recent years. Based on its distinctive high-speed and cutting-edge nature, the airport industry plays an important role in promoting local economic development and the conversion of new and old kinetic energy. The research team found based on previous research that flexible talent introduction has injected a certain vitality into the development and management of talents in the airport industry in City G, but it has also encountered a series of new issues, such as lagging policy support, lack of incentives for assessment and evaluation, and disconnection of talent services. The problem, therefore, the intensity of talent introduction is not competitive, and the effect of talent introduction is not obvious. Looking at the Guangdong-Hong KongMacao Greater Bay Area and the flow and sharing of high-level talents around the world, how can the airport industry in City $G$ effectively overcome the shortcomings of flexible talent introduction and lack of services, and how to gain advantages in human resources through various methods, so as to obtain sustainable talents Motivation and competitiveness are more worth exploring. Based on the above-mentioned reality, this article will investigate the problems of flexible talent introduction policies, channels and targets of the airport industry in $\mathrm{G}$ City from the perspective of talent governance, analyze the reasons, and explore its mechanisms and countermeasures, in order to promote the development of the airport industry to a higher level, and contribute more to the construction of an international metropolis in City $\mathrm{G}$ and the construction of the Guangdong-Hong Kong-Macao Greater Bay Area.

\section{The origin of talent governance and the literature review of flexible talent introduction}

Regarding "talent governance", from the important thesis of "respecting knowledge and respecting talents" first put forward by Comrade Deng Xiaoping in May 1977 , to the strategy of strengthening the country through talents established in 1978-2003, China's talent development governance system has been continuously improved and initially formed. A talent governance model that meets the requirements of reform, opening up and economic construction. In 2016, the term "talent governance" appeared for the first time in the "Opinions on Deepening the Reform of the Talent Development System and Mechanism" issued by the Central Committee of the Communist Party of China, as a strengthening and tension in the field of "national governance system and governance capability modernization". "Talent governance" gives the employer greater autonomy and flexibility. From the perspective of

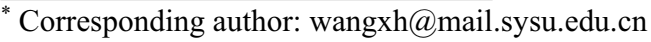


public governance, talent governance emphasizes both the "coordination" of multiple subjects (Sun Rui, Wu Jiang, 2019) and teamwork (Zhu Xunke, 2019). Regarding the flexible introduction of talents, as a measure of talent governance, it has been fully presented in terms of policies and has been widely reported in the news media. For example, G Province has more than a dozen policies on flexible ways of attracting talents. In the past two years, G Province's news media have reported more than 4,000 practical and applied results. However, searching for "flexible talent introduction" on CNKI only found more than 100 journal articles, mainly focusing on the research on the "migratory bird-type" talent innovation management service model in underdeveloped regions, the exploration of the shortage of high-tech talents in relatively developed regions, and the exploration of new technologies. Research on flexible agglomeration of industrial talents, etc. Research on the motivation, logic and path of the introduction model is relatively lacking, especially the research on the introduction of talents in the airport industry is still blank. In 2019, the "Gathering Talents Program" integrated and promulgated by City $\mathrm{G}$ did not pay enough attention to the policy of airport industry talents. At present, it has not yet established a high-end, open, refined, and combined talent policy system for airport industry talents. In summary, with the continuous improvement of the party and the country's governance concepts, governance systems, and governance capabilities, the exploration and practice of talent development governance reforms continue to be enriched. Domestic scholars mainly focus on research on talent governance and talent policy, but lack specific research on a specific industry, industry or a certain talent introduction mechanism. "Talent governance" belongs to the category of public governance, and the core of public governance is the collaboration of governance entities in a staggered and complex environment (O'Toole, Laurence J.1997), [3] and the need for multiple organizations to collaborate in order to better Problem solving (Acar Muhittin, Guo chao, and Saxton Gregory D.) .[4]The United States, Germany, Japan, etc. have all promulgated relevant talent development laws and regulations, realizing that the governance method relies on the rule of law and norms, which is the second. Third, in terms of governance capabilities, developed countries focus on digitalization, which reflects modernity and science. Fourth, in terms of governance structure, all countries have sound talent policy systems, talent evaluation systems, and talent security systems. Fifth, in terms of governance content, some scholars propose to emphasize differentiation and focus on cultivating creative and innovative scientific and technological talents (abdulah, 2017); some scholars emphasize field, for example, Kurt Lewin believes that $\mathrm{B}=\mathrm{f}(\mathrm{P}, \mathrm{E})$ This behavior model will be restricted by individuality and environmental factors. Therefore, it is recommended to fully understand various talent constraints, and improve the strategic height of talent governance by designing appropriate talent policies and talent management environments; some scholars emphasize international Talent mobility and talent governance should adapt to the new situation of globalization and give full play to the innovation and creativity of talents (Lesleyanne Hawthorne, 2010). Generally speaking, foreign research on talent governance is relatively scattered, showing a trend of multiple perspectives, and more cases are used to study flexible talent introduction. However, most foreign studies have selected effective theoretical support, such as human capital theory, talent flow theory, atypical employment theory, etc., to construct a relatively complete theoretical framework and provide a theoretical basis for the flexible introduction of follow-up research.

\section{An Empirical Study of Flexible Talent Attraction in the Airport Industry: Problem and Cause Analysis}

\section{Types of talents the company needs}

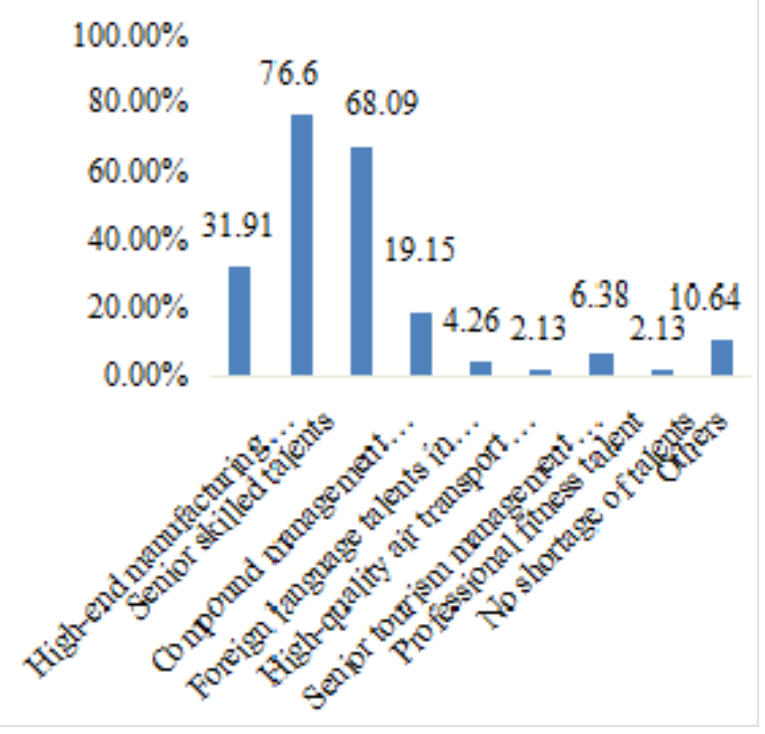

Fig. 1. Types of talents needed for flexible introduction.

Big In order to study the flexible introduction of talents in the airport industry in City G, this research covers the major industries of the airport industry, such as high-end manufacturing, high-tech industries, aviation maintenance, aviation manufacturing, and transportation logistics. We first conducted an in-depth review of the relevant persons in charge of $G$ Aircraft Maintenance Engineering Co., Ltd., S Airlines G Branch, Z Airlines Cargo Co., Ltd., as well as the management committee of the Airport Industrial Park and the staff of the local government's human resources department. Through the interview, we have a preliminary understanding of the value of the flexible talent introduction model in the development and management of airspace industry talents in the region. Then, 47 senior managers from 20 companies and 153 employees from 16 companies were selected to conduct a questionnaire survey. Which talents does the airport industry in G City need to introduce flexibly? Among the above-mentioned companies participating in the survey, $76.6 \%$ of the companies put forward the demand for high-skilled talents; $68.09 \%$ of the companies put forward the demand for compound 
operation and management talents; $31.91 \%$ of the companies put forward the demand for high-end manufacturing and scientific research talents; $19.15 \%$ of the companies put forward the demand for foreign language talents for cross-cultural communication (as shown in Figure 1). The following will summarize and analyze the research situation from three levels.

\subsection{At the level of talent introduction policy: the policy system has insufficient support for talent demand and talent introduction model}

At the level of talent introduction policies, we found that the airport industry lacks innovative talent support policies. The survey shows that $85.19 \%$ of companies expect to formulate a talent policy system for the airport industry in the future. The survey shows that $78.4 \%$ of talents are very concerned about the fit between talent assessment and the airport industry. In actual work, the recognition of talents in City $\mathrm{G}$ is mainly implemented in accordance with the "City G High-level Talent Recognition Program" (2018) and "G City High-level Talent Recognition Standards" (2017). There are three high-end talent levels: "Excellent Expert" and "G City Youth Reserve Talent". The threshold of the aforementioned talent identification policy is too high, and the talents actually required by the airport industry cannot meet this standard, and thus cannot enjoy policy support. For example, and flight attendants), which are different from the assessment of general professional qualifications or technical titles. The demand for supporting talents is the most direct guiding demand and should be included in the top-level design of the talent policy. The second is to ignore the individual needs of special industries, leading to deviations in landing.

\subsection{In terms of talent introduction channels: diversified talent introduction models and insufficient openness}

In general, it is flexible to attract talents, and more attention is paid to the introduction of talents that are in short supply. According to the research conducted by the research team from the corporate perspective, $40.43 \%$ of the companies introduced from the city, $34.04 \%$ from other provinces, and about $23.4 \%$ from other cities in the province, $2.31 \%$ Companies will introduce needed talents from abroad (overseas), as shown in Figure 2. In addition to external introduction, most companies acquire talents through internal training $(74.47 \%)$ and employee recommendation (31.91\%). In addition, companies will also use headhunting companies, schoolenterprise cooperation, talent markets outside the province, and overseas talent markets. Recruitment, etc., as shown in Figure 2.

The research team conducted research from the perspective of talents to explore how talents can join the airport industry. Among the airport industry personnel participating in the survey, most of them joined the airport industry mainly through online recruitment (31.37\%), acquaintance recommendation $(30.07 \%)$, and campus recruitment (11.76\%). A small number of personnel joined the industry through headhunting companies $(2.61 \%)$, the government takes the lead in the job fair $(0.65 \%)$ to join the airport industry, as shown in Figure 3. Specific to how various types of talents join the airport industry, the survey found that whether it is management talents, professional technical talents, R\&D talents, high-skilled talents, international talents, marketing talents, and even ordinary workers, they mainly rely on recommendations from acquaintances, as shown in Figure 4.

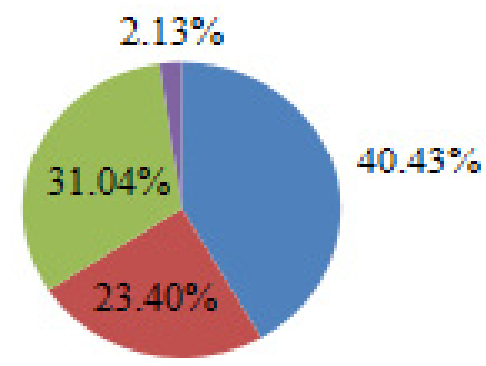

\section{Introduced by the city \\ Introduced by other cities in the province Few introductions from other provinces Imported from abroad}

Fig. 2. Target areas for companies to recruit talents in short supply

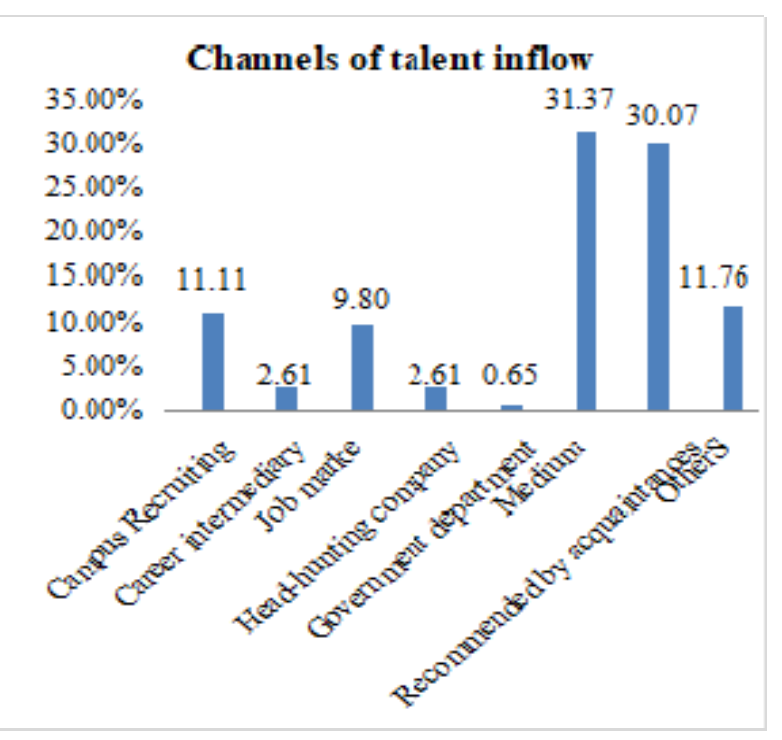

Fig. 3. How companies recruit talents 


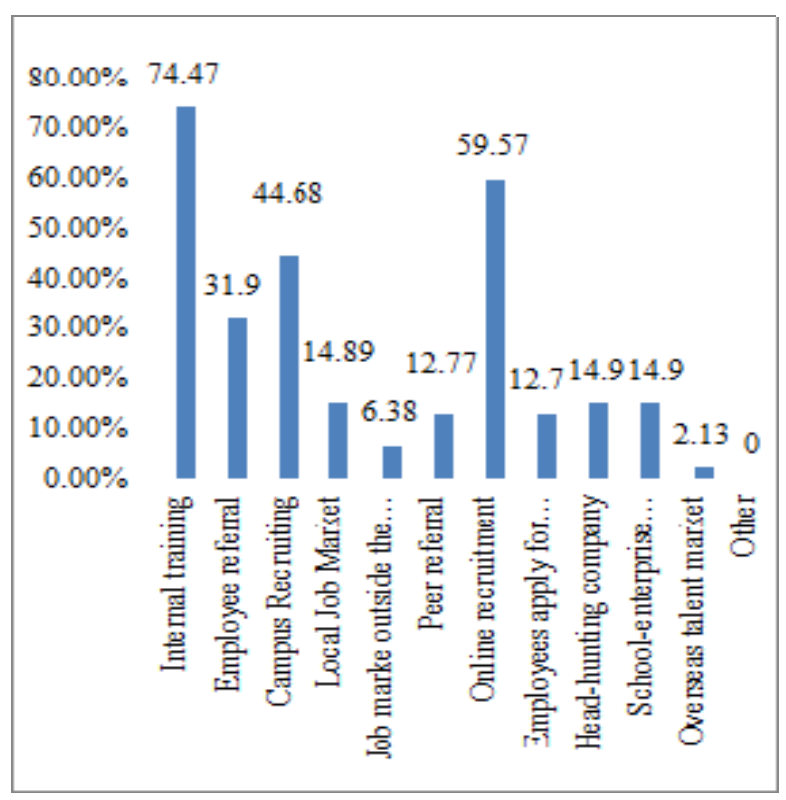

Fig. 4. Talent inflow channels

\subsection{In terms of attracting talents: emphasis on high-level talents and despise high-potential talents}

The flexible talent recruitment of enterprises investigated in this project focuses on "attracting" high-level talents, and attracts high-level talents at home and abroad by providing economic incentives as incentives; research and interviews from the perspective of talents found that high-level talents are not good for economic factors Distributed attention makes the introduction of highlevel talents difficult to achieve smoothly. Generally speaking, high-level talents are successful people who have already achieved achievements and have a good working platform. If the policies and services that are introduced flexibly are not in place, it will be more difficult to attract them. Another group of talents, highpotential talents, is often overlooked. High-potential talents generally have excellent potential but have not yet achieved fame. They need an environment for growth and development and a working platform to give full play to their expertise. Therefore, they pay more attention to career development and economic incentives. First, under the guidance of high-level talent policy, companies tend to think within the scope of policy protection, which restricts the expansion of corporate thinking to a certain extent; second, under the guidance of industrial development, companies' talent strategy thinking is too conservative and common There is a lack of clear and clear criteria and procedures for evaluating high-potential talents.

\section{Suggestions on the flexible talent introduction mechanism of airport industry in $\mathbf{G}$ city from the perspective of talent governance}

Based on the empirical evidence and analysis of the above survey, this research will use the perspective of talent governance to propose countermeasures and suggestions for the flexible talent introduction mechanism of the airport industry in G City from the perspective of collaborative governance, dynamic governance, and risk governance.

\subsection{Based on the concept of collaborative governance, emphasizing the collaboration of governments, industries, and enterprises to promote talent policy innovation}

Due to the lack of industry specificity in the existing talent policy of City $\mathrm{G}$, and the overlapping and mixing of industrial talent policy and investment policy, which did not effectively highlight the bright spots and characteristics of airport talent demand, the research team believes that reforms can be made from the perspective of diversified governance. [5] From a specific operational level, the first is to establish and improve a leading agency for talent work in the airport industry. The government is responsible for organizing the evaluation and investigation of talent introduction and development. Flexible introduction; At the same time, it formulates highly targeted flexible introduction and development policies for talents, regularly carries out follow-up investigations and studies, and publishes white papers on talent development and management in the airport industry to ensure the support of talent policies. The second is to improve the communication between government and enterprises, promote the formation of joint forces between industries, enterprises and the government, enhance mutual trust between government and enterprises, and build effective communication channels between government and enterprises, so as to collect enterprise needs, feedback and other relevant opinions in a timely manner to prevent implementation deviations and distortions.

\subsection{Based on the concept of dynamic governance, emphasizing innovative methods and flexible methods to attract talents}

The concept of dynamic governance believes that new governance models should be constructed with the development of the environment. The flexible talent introduction of the airport industry is still based on "waiting for you", which can play a certain role in the era of rigid talent introduction. Under the open pattern of flexible talent introduction, the original rigidity of talents is not easy to change, but the diversified flexible mode is urgently needed to be explored by the talent demand side. On the one hand, through the construction of a talent service industrial park, a precise talent introduction model will be created. Accelerate the introduction of 
human resource service providers, establish a digital sharing platform for talent information, and develop and expand platforms such as Upwork, Freelancer, Crew, etc.; focus on cultivating talent management consulting, talent search, training and development and other talent service organizations to be high-level talents And provide hardware support for the precise introduction of high-potential talents. On the other hand, continue to build high-level talent clubs and explore the characteristic recommendation system in the region. It is recommended that the government take the lead in holding a high-potential talent exchange meeting, and according to the talent demand for the development of the airport industry, introduce high-qualified and highpotential talent teams at home and abroad to build a bridge between industry demand and the supply of highlevel and high-potential talents.

\subsection{Based on the concept of risk management, emphasizing the introduction of high-potential talents and the establishment of a talent evaluation system}

Ulrich Beck of Germany believes that risk is a byproduct of development. The concept of risk governance will awaken the sense of responsibility for talent governance and will inevitably urge us to pay attention to the difficulty of introducing high-level talents and the risks of barriers in talent evaluation in top-level design. The incentives provided by the Airport Industrial Economic Zone are more attractive to high-potential talents. High-potential talents pay more attention to career development and economic incentives, and are more likely to accept incentives provided by enterprises to join the airport industry. Second, to innovate the airspace talent evaluation mechanism, promote the reform of professional title evaluation in industries (such as the aviation maintenance industry), and build an evaluation system for high-potential talents. It is recommended to learn from Xiamen's aviation maintenance industry's professional title evaluation reform, and closely connect and deeply integrate talents and professional title work with the needs of the airport industry, so that talents who make contributions will have a sense of accomplishment and gain. Development provides strong talent support.

\section{Conclusion}

As an important engine of city and regional economic development, the airport economy of City $G$ is still inseparable from talents for its core competitiveness. Although the importance of talents as the primary resource is unquestionable, it is even more urgent for the high-speed and high-end airport industry that special needs, highly sophisticated talents join. Through research, this research has promoted the transformation of talent introduction model on the one hand, and has gradually moved from rigid talent introduction to more targeted flexible talent introduction; on the other hand, it has promoted top-level design at the level of talent governance, emphasizing collaboration in talent work The concepts of governance, dynamic governance, and risk governance, especially the mechanism to ensure that "flexible" talent policies, landing methods, and evaluation systems can fully serve the development of the airport industry. Although after investigation and empirical analysis, this article has mastered the talent data of the airport industry in City $G$ and unearthed the related pain points of attracting talents, but how do these pain points affect the degree of aggregation of the airport economy and the development of the growth pole model? From the research perspective, I haven't explored it in depth yet. In future research, more quantitative research methods can be used to further explore the relationship between the leading factors of talent introduction pain points and the development status variables of the airport industry, with a view to formulating a more flexible and flexible talent introduction mechanism.

\section{Acknowledgements}

This article is one of the phased achievements of the "2020 Dongguan City Philosophy and Social Science Planning Project "Research on the Flexible Talent Induction Mechanism in the Construction of Dongguan Talent Highland"" and "The Research Project of the Postdoctoral Innovation Base for Harmonious Labor Relations of the Human Resources and Social Affairs Bureau of Huadu District, Guangzhou" One.

\section{References}

1. R.Sun, J.Wu, Research on the construction of the governance system for talent development in the new era under the background of innovation-driven , Chinese Administration, (07): 35-40(2020)

2. X.K.Zhu, S.B.Zhu, M.Tang, Talent Governance: Framework System and Basic Strategies: Thinking of Studying Xi Jinping's Important Statements on Talent Work, Journal of Zhaotong University, 41(04):1-10( 2019)

3. O'Toole, J. Laurence, Treating Networds Seriously: Practical and Research-based Agendas in Public Administration, Public Administration Review, 57(1), pp45-52(1997)

4. M.Acar, C.Guo and D.G.Saxton, Managing Effectively in a Networked World, The Public Manager, 36(2),p.23(2007)

5. B.Liu, Y.S.Zhu, L.Liang, Research on the Identification and Governance Strategies of Multiple Governance Subjects in the Reconstruction of Human Resources in Xiong'an New District, China Human Resources Development, 8: 69-79(2019) 